\title{
Ehlers-Danlos syndrome associated with cleft lip and palate
}

Pearlie WW Tan MBBS MRCS ${ }^{1}$, Colin Song MBBCh FRCS(Plast $)^{1}$, Donald Lalonde MSc MD FRCSC ${ }^{2}$

PWW Tan, C Song, D Lalonde. Ehlers-Danlos syndrome associated with cleft lip and palate. Can J Plast Surg 2009;17(4):e24-e26.

Ehlers-Danlos syndrome (EDS) is a hereditary connective tissue disorder caused by abnormal collagen synthesis and presents with classic features of hyperextensibility, fragility of skin and joint hypermobility. It has not been commonly described as being associated with cleft lip and/or palate, and a literature search has disclosed only one case (1984) of type IV EDS with cleft lip and palate. The authors have seen another case of EDS associated with cleft lip and palate. The etiology and clinical features of this syndrome are discussed alongside the clinical picture of cleft lip and palate.

Key Words: Cleft lip and palate; Ehlers-Danlos Syndrome

\section{CASE PRESENTATION}

On a surgical mission trip to Hyderabad, India, a 17-year-old girl presented to the preoperative screening centre. A secondborn child to normal parents, she was born with a complete left-sided unilateral cleft lip and palate (Figure 1), and

\section{Un syndrome d'Ehlers-Danlos associé à un bec-de-lièvre et à une fissure palatine}

Le syndrome d'Ehlers-Danlos (SED) est une maladie génétique du tissu conjonctif causée par une synthèse anormale du collagène et qui se manifeste par des caractéristiques classiques d'hyperextensibilité, de fragilité de la peau et d'hyperlaxité des articulations. Il n'a pas souvent été décrit en association avec un bec-de-lièvre, une fissure palatine ou les deux. Une analyse bibliographique n'a permis de repérer qu'un cas (1984) de SED de type IV lié à un bec-de-lièvre et à une fissure palatine. Les auteurs en ont observé un deuxième cas. Ils exposent l'étiologie et les caractéristiques cliniques de ce syndrome ainsi que le portrait clinique du bec-de-lièvre et de la fissure palatine.

according to her mother, abnormalities in her legs, which resulted in her not being able to walk, only mobilizing by 'bottom shuffling' and crawling since birth. She had an older brother who was physically normal, and no known family history of congenital anomalies. A previous lip repair was
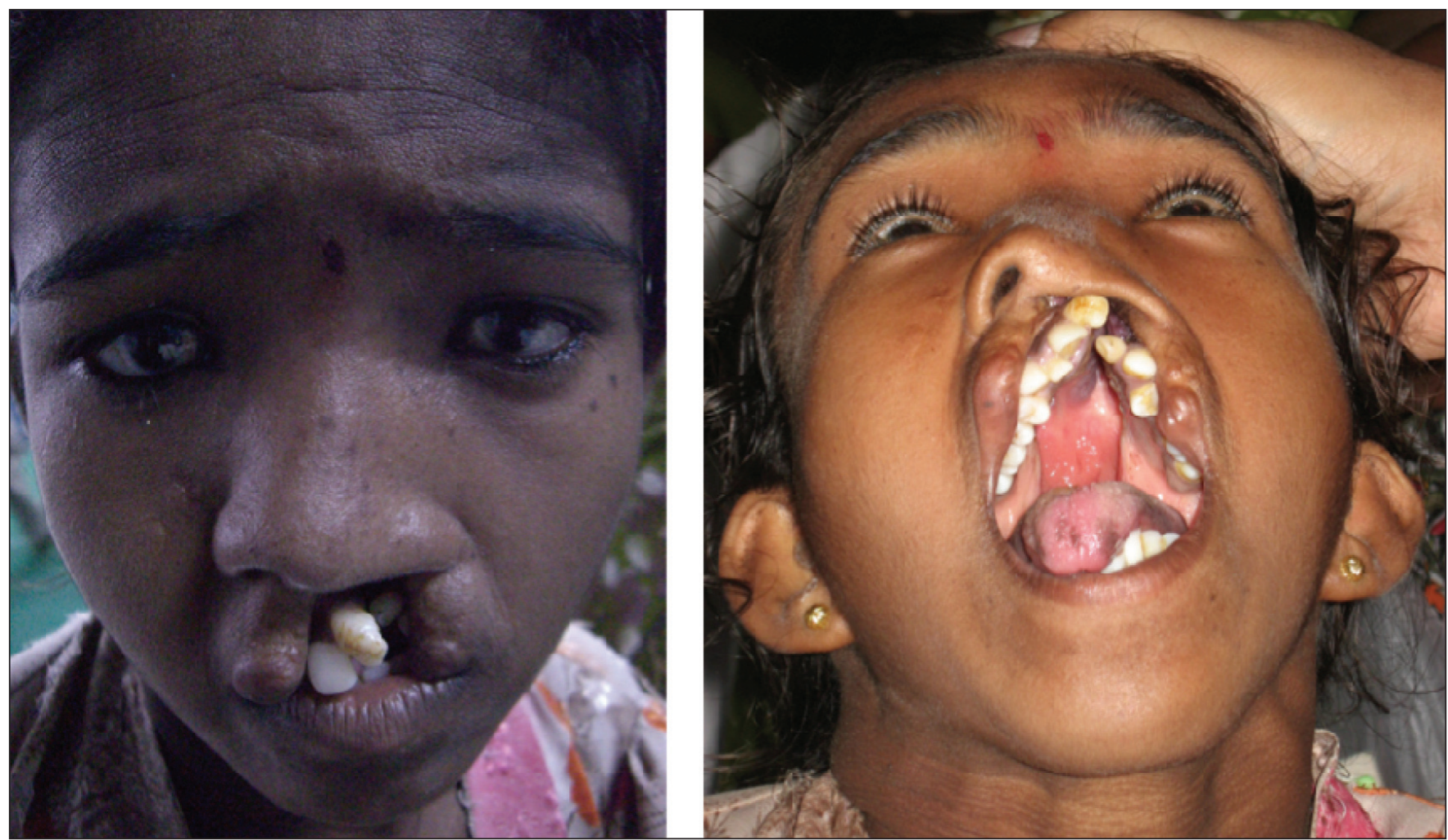

Figure 1) Previously repaired and dehisced cleft lip and palate

${ }^{1}$ Plastic, Reconstructive and Aesthetic Surgery, Singapore General Hospital, Singapore; ${ }^{3}$ Dalhousie University, Saint John, Newfoundland Correspondence: Dr Pearlie WW Tan, Department of Plastic, Reconstructive and Aesthetic Surgery, Singapore General Hospital, Outram Road,

Singapore 169608. Telephone 65-82827809, fax 65-63213804, e-mail drpearlietan@gmail.com 

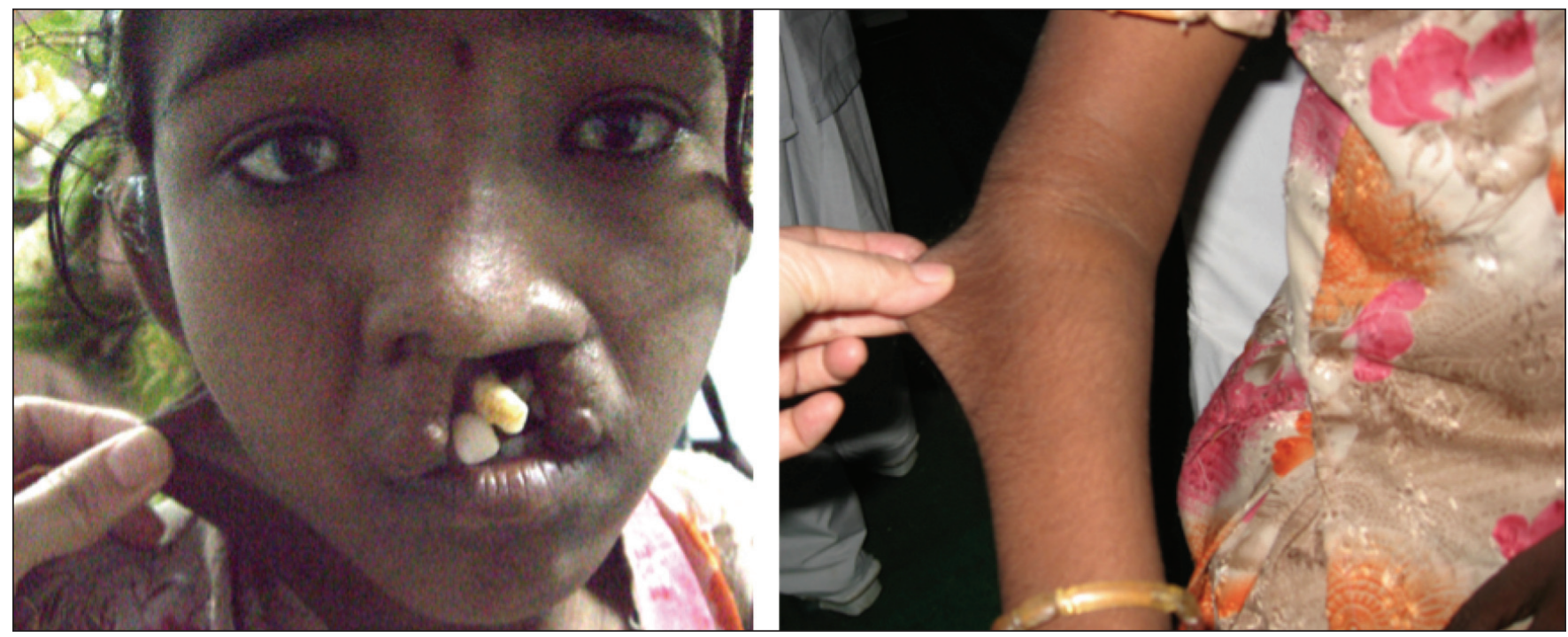

Figure 2) Hyperelasticity of skin

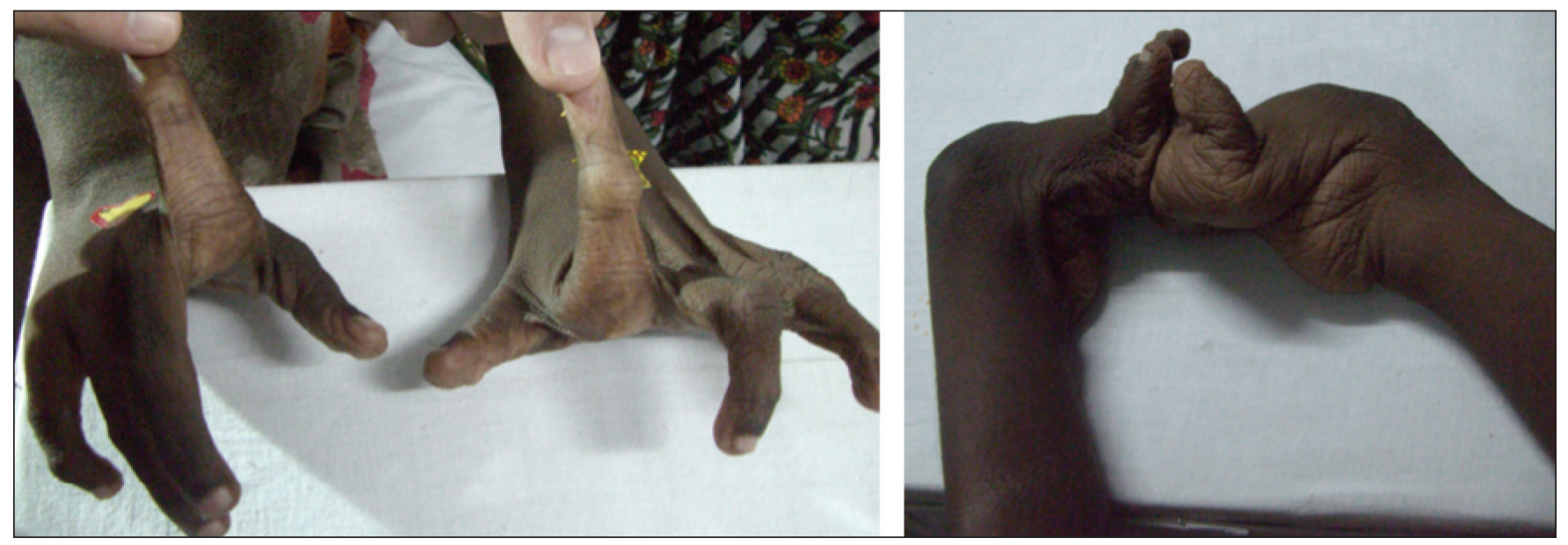

Figure 3) Hypermobile finger joints (left panel) and club foot (right panel)

performed at the age of six years but according to her mother and aunt, the wound broke down when she fell a few weeks postoperatively. This we suspect was a wound dehiscence and the fall was a coincidental event. Her mother denied her daughter having a tendency to bruise easily after light trauma, but admitted her wounds did take a long time to heal, subsequently forming paper-thin scars. They lived in a village where the patient stayed mostly indoors and performed most household chores.

Physical examination revealed a physically handicapped slender girl with marked facial dysmorphic features: frontal bossing, hypertelorism, down-sloping palpebral fissures and down-slanting eyes, a flattened nasal bridge and a left-sided unilateral complete cleft lip and palate. Her skin had a soft velvety quality, and it was possible to stretch it in folds several centimetres deep, especially in the region of the neck and arms (Figure 2). The subcutaneous fat was poor and the muscles were markedly hypotonic. There was profound laxity of large and small joints, and she had marked laxity of the metacarpophalangeal and interphalangeal joints (Figure 3), and swan neck deformities of the fingers. She also complained of tender molluscoid pseudotumours over pressure points in her palms.
She was unable to walk and moved by bottom shuffling on her right hip with left knee flexed; according to her mother, this has been the way she mobilized all through childhood. She had bilateral clubfoot with an interesting crisscrossing pattern in her soles. We also noted cigarette paper-like scars and an obvious lack of ecchymosis in the skin.

A cardiovascular and respiratory examination were unremarkable.

From the above findings of skin hyperelasticity and hypermobility of joints, Ehlers-Danlos syndrome (EDS) associated with cleft lip and palate was diagnosed. This was explained to her mother along with the risks of surgery and anesthesia. Her family expressed that they were not overly concerned with her facial appearance, but rather it was her legs that they were requesting surgery for. The nature of this connective tissue disease was explained and they became reluctant to subject their daughter to the risks of surgery and anesthesia for a condition they had grown used to. Therefore, it was decided she was not for any surgical intervention. She was subsequently put into contact with a free occupational therapy service near the village for leg braces and appliances to pad the pressure areas in her limbs. 


\section{DISCUSSION}

EDS is caused by a disorder of collagen tissue due to a hereditary enzyme deficiency during the biosynthesis pathway. It is genetically transmitted in an autosomal dominant, recessive or sex-linked fashion with incomplete penetrance. Typical histological findings on skin biopsy show disorderly arranged dermal collagen fibres with a whorled appearance, while laboratory investigations of clotting factors, platelet aggregation and bleeding time are usually within normal limits, as in most connective tissue disorders (1).

This is one of the oldest known causes of bruising and bleeding and was first described by Hippocrates in 400 BC.The syndrome is named after Edvard Ehlers, a Danish dermatologist, (1863-1937) and Henri-Alexandre Danlos, a French dermatologist (1844-1912) (2). In 1936, an English physician, Frederick Parkes-Weber, suggested that the disorder be named 'Ehlers-Danlos syndrome' (3). One in 5000 people are affected by EDS (4) and it affects males and females equally of all racial backgrounds (5).

Originally, an international nosology of connective tissue disease defined nine subcategories of EDS (1988). With recent advances in our understanding of its biochemical and molecular pathology, a simplified classification according to the Villefranche nosology revised EDS into six major types (6). Now, the classification of EDS is based on the extent and severity of the classic clinical features and coexistent abnormalities, the most likely pattern of inheritance, and the results of biochemical and molecular analyses on each type of unique abnormal collagen metabolism (6).

In our case report, the present patient presents features most consistent with that of EDS type VII (arthrochlasia type), which is characterized by severe generalized joint hypermobility, with recurrent joint subluxations of both large and small joints; previous case reports of type VII EDS have also shown congenital bilateral clubfoot, arthrogryphosis of hands and feet, congenital bilateral hip dislocations at birth and marked muscular hypotonia. Characteristic facial appearance varies among the three subtypes of EDS VII ( $a, b$ and $c)$, with reports of facial dysmorphic features of frontal bossing, hypertelorism, depressed nasal bridge, macrostomia and bluish sclerae. Additional case reports have also described cutis laxa and a crisscross patterning of hands and feet (5); instability of knees and ankles precluding weight bearing and necessitated ambulation by means of 'bottom shuffling' or wheelchair. In type VII EDS, skin changes have been described as less severe than the other that of patients with type I EDS, which is the classic form of the disorder (6), with some cases reporting normal bruising. In our case, it was highlighted by our patient's mother that there was no out of the ordinary bruising in response to light trauma. Poor wound healing and atrophic scarring is a common feature to all types of EDS, more prominent in some types than others, and in this case, we noted her cigarette paper-thin scars.

There has been one case of EDS type IV associated with cleft lip and palate reported in 1986 (7). The authors described a six-year-old Japanese girl of normal parents with a complete left-sided cleft lip and palate who had a lip plasty done at the age of six months and presented to the authors for elective palatoplasty. She was described as having highly retarded physical and intellectual development and no tendency to bruise easily after light trauma. She showed characteristic facial dysmorphism (hypertelorism and antimongoloid type of palpebral fissures), soft velvety skin and markedly hypotonic joints. Likewise to this case, no skin biopsy was obtained and diagnosis of the type of inherited EDS relied on the distinct characteristics and common manifestations of specific types of EDS.

\section{CONCLUSION}

There have been a number of small case series of generalized connective tissue disorders associated with cleft lip and/or palate (eg, Kabuki syndrome [8] and Strickler syndrome [9]). There exists a possible mechanistic relationship between connective tissue disorders and failure of fusion of the nasal prominences of the fronto-nasal process and maxillary prominence in cleft lip and failure of fusion of the lateral palatal processes in cleft palate; however, this has not been fully elucidated. It is as likely as the above connective tissue disorders described that a subtype of EDS may be associated with cleft lip and/or palate and we look forward to more case reports of this relationship.

\section{REFERENCES}

1. De Paepe A, Malfait F. Bleeding and bruising in patients with EhlersDanlos syndrome and other collagen vascular disorders. Br J Haematol 2004;127:491-500.

2. Parapia LA, Jackson C. Ehlers-Danlos syndrome - a historical review. Br J Haematol 2008;141:32-5.

3. Enerson OD. Ehlers-Danlos syndrome <www.whonamedit.com/synd. $\mathrm{cfm} / 2017 . \mathrm{html}>$. (Version current at September 2, 2008).

4. Pyeritz RE. Ehlers-Danlos syndrome. N Engl J Med 20009;342:730-2.

5. Ceccolini E, Schwartz R. Ehlers-Danlos syndrome <www.emedicine. com>. (Version current at September 2, 2008).

6. Breighton P, De Paepe A, Steinmann B, Tsipouras P, Wenstrup RJ. Ehlers-Danlos syndromes: Revised nosology, Villefranche, 1997. Ehlers-Danlos National Foundation (USA) and Ehlers-Danlos Support Group (UK). Am J Med Genet 1998;77:31-7.

7. Okamura H, Matsumoto Y. A case of Ehlers-Danlos syndrome associated with cleft lip and palate. J Laryngol Otol 1984;98:311-5.

8. Burke LW, Jones MC. Kabuki syndrome: Underdiagnosed recognizable pattern in cleft palate patients. Cleft Palate Craniofac J 1995;32:77-84.

9. Lee KH, Hayward P. Retrospective review of Stickler syndrome patients with cleft palate 1997-2004. ANZ J Surg 2008;78:764-6. 